\title{
Use of oral contraceptives in the management of acne
}

This article was published in the following Dove Press journal:

Open Access Journal of Contraception

I4 November 20I I

Number of times this article has been viewed

\section{Gian Benedetto Melis \\ Marisa Orrù \\ Maria Francesca Marotto \\ Monica Pilloni \\ Mariagrazia Perseu \\ Stefano Lello \\ Anna Maria Paoletti \\ Clinica Ginecologica Ostetrica e di Fisiopatologia della Riproduzione Umana, Universita' di Cagliari, Azienda Ospedaliero Universitaria di Cagliari, Cagliari, Italy}

Correspondence: Gian Benedetto Melis Azienda Ospedaliero Universitaria di Cagliari, Via Ospedale 54, 09124 Cagliari, Italy

Tel +390 70652797

Fax +39070668575

Email gineca.annapaoletti@tiscali.it
Abstract: The pathogenesis of acne (the most common disorder involving the sebaceous gland) originates from increased sebum production by the sebaceous gland followed by colonization of the hair follicle with Propionibacterium acnes, hyperkeratinization of the upper follicle, and release of inflammatory mediators into the skin. Androgens are the main stimulators of sebum production. Androgens originate from the gonads and adrenal glands, but can also be locally produced within the sebaceous gland from dehydroepiandrosterone sulfate. In the presence of high androgen levels, which can be either a normal pattern of adolescence or a consequence of gonadal or adrenal disease, overproduction of sebum triggers the pathogenesis of acne which, mainly in adolescent women, has deleterious psychological consequences. Estrogens exert the opposite action on sebum production, probably due to the reduction of androgen availability, a direct consequence of estrogen-related increased production of hepatic sex hormone-binding globulin (SHBG). The inhibition of the hypothalamus-pituitary axis induced by oral contraceptives is followed by reduced androgen production. Oral contraceptives containing ethinyl estradiol, which has strong estrogenic activity, amplify the hypoandrogenic effect via estrogenrelated stimulation of SHBG. The hypoandrogenic effect of oral contraceptives is modulated by the progestin compound. Progestins derived from 19-nortestosterone bind androgenic receptors, whereas others exert antiandrogenic properties by antagonizing the binding of androgens to their receptors, reduce $5 \alpha$-reductase, and do not bind SHBG. Through this last effect, SHBG is freely available to bind androgens, and the same progestin is totally free to exert its antiandrogenic properties. After correct evaluation of the cause of acne, appropriate management can be undertaken using oral contraceptives containing low daily doses of ethinyl estradiol (20 or $30 \mu \mathrm{g}$ ) associated with a progestin compound, such as cyproterone acetate, drospirenone, or chlormadinone acetate, the antiandrogenic activity of which has been demonstrated by many studies in animals and in humans.

Keywords: acne, progestins with antiandrogen properties, sex hormone-binding globulin

\section{Introduction}

Acne vulgaris is an extremely prevalent skin condition, affecting the majority of teenagers. The quality of life of young women is highly compromised as a result of the negative influences on emotional and social functioning provoked by this medical condition, with esthetic consequences, so much so that acne-affected adolescent women often suffer from anxiety, depression, and reduced self-esteem. ${ }^{1-6}$ Acne is an important issue for adult women also. In fact, $25 \%$ of adult women in the US have ongoing adult acne. ${ }^{7}$

The pathogenetic factors involved in acne represent a specific target for its treatment. Excessive sebum production by sebaceous glands triggers development of 
acne, although many subjects with normal sebum production also have acne. ${ }^{8}$ Abnormal desquamation of the epithelium in the follicle inside the duct of the sebaceous gland, proliferation of Propionibacterium acnes, and inflammatory and immunological responses are all factors which impair skin function. All the mechanisms involved in sebum production need to be understood to treat the primary cause of acne. ${ }^{9}$

\section{Regulation of sebum production}

Sebum production is continuous and is not controlled by a neural mechanism. Androgens and growth hormones promote differentiation of the sebaceous glands, whereas estrogens and retinoids inhibit differentiation. ${ }^{10-14}$

\section{Androgens}

The majority of circulating androgens are produced by the gonads and adrenal glands. Testosterone and dihydrotestosterone are potent androgens. They form complexes with nuclear androgen receptors. The androgen-receptor complex interacts with DNA in the nuclei of sebaceous cells to regulate genes involved in cell growth and lipid production. ${ }^{15,16}$

Dihydrotestosterone is the most potent androgen. Its synthesis is regulated by activity of the type 1 isoenzyme of $5 \alpha$-reductase. This enzyme converts testosterone into dihydrotestosterone in the sebaceous glands. ${ }^{17,18}$ In the absence of high circulating levels of androgen, increased activity of this enzyme leads to overstimulation of sebum formation as a result of higher dihydrotestosterone availability. ${ }^{19,20}$ Androgens can also be produced locally within the sebaceous glands from the adrenal precursor hormone, dehydroepiandrosterone sulfate (DHEAS). The first step is a dehydrogenization, regulated by $3 \beta$-hydroxysteroid dehydrogenase, through which DHEAS is converted into androstenedione. Thereafter, the reversible conversion of androstenedione into the more potent androgen, testosterone, is catalyzed by $17 \beta$-hydroxysteroid dehydrogenase. ${ }^{21}$ The last step in the synthesis of dihydrotestosterone from testosterone is promoted by the type 1 isoenzyme of $5 \alpha$-reductase. ${ }^{15,16}$ Recent evidence shows that the skin and sebaceous glands themselves are capable of producing androgens. They are able to synthesize cholesterol de novo from acetate, and they have the enzymes necessary for the next steps in androgen synthesis. ${ }^{22-24}$

\section{Estrogens}

It is known that estrogens decrease sebum production. One mechanism through which estrogens exert this effect is probably their action against the availability of androgens at their receptors in the sebaceous glands. Estrogens increase the hepatic production of sex hormone-binding globulin which binds androgen molecules. Increased sex hormone-binding globulin levels indicate that an equivalent number of androgen molecules is not available to link their receptors. ${ }^{25}$

\section{Clinical management of acne}

Figure 1 shows the sources of androgens in women. The zona reticularis of the adrenal glands and the ovarian stroma are the main androgen-producing tissues. However, the liver is also represented (Figure 1) in relationship to its modulatory role in the production of sex hormone-binding globulin, and several factors can influence production of sex hormonebinding globulin in the liver (see Table 1). The pilosebaceous unit plays a key role in local androgen availability. Idiopathic hirsutism $^{19}$ is a state of hyperactivity of $5 \alpha$-reductase in peripheral tissues that leads to increased conversion of normal levels of testosterone into dihydrotestosterone, and ultimately to peripheral manifestations of hyperandrogenism, such as acne and hirsutism. ${ }^{19,20}$ In the event of sudden appearance of acne, especially if associated with other hyperandrogenic symptoms (hirsutism, alopecia, virilization), it is mandatory to exclude an adrenal or ovarian tumor. In these cases, circulating androgen levels are very high and surgical removal of the tumor is necessary. In acne related to other hyperandrogenic conditions, overstimulation of the pilosebaceous gland should be antagonized in order to improve the skin disorder and to reduce exaggerated stimulation of androgen receptors in other tissues. The latter activity is responsible for some metabolic disorders, such as impaired glucose metabolism, lipoprotein synthesis, and deleterious effects of androgens on the arterial wall. ${ }^{26}$ In studies reported by our group ${ }^{27}$ and of other researchers, ${ }^{28-30}$ a metabolic pattern of insulin resistance and hyperinsulinemia is present not only in women suffering from polycystic ovary syndrome, but also in women with idiopathic hirsutism. In addition, our as yet unpublished research shows that the same impairment of insulin metabolism can be found in other hyperandrogenic conditions (Table 2). Finally, hyperinsulinemia dependent on androgen overstimulation, in any case of hyperandrogenism, can stimulate androgen secretion from both the ovarian and adrenal glands (Figure 2).

A hyperandrogenic state is a peculiar characteristic of adolescence, comprising a primary increase of adrenal androgens followed by androgen steroidogenesis in the ovary (Figure 3). This process of steroidogenesis is further stimulated by a direct effect on ovarian stromal cells by insulin and insulin-like growth factors, increased circulating levels of which depend on concomitant activation of the growth 


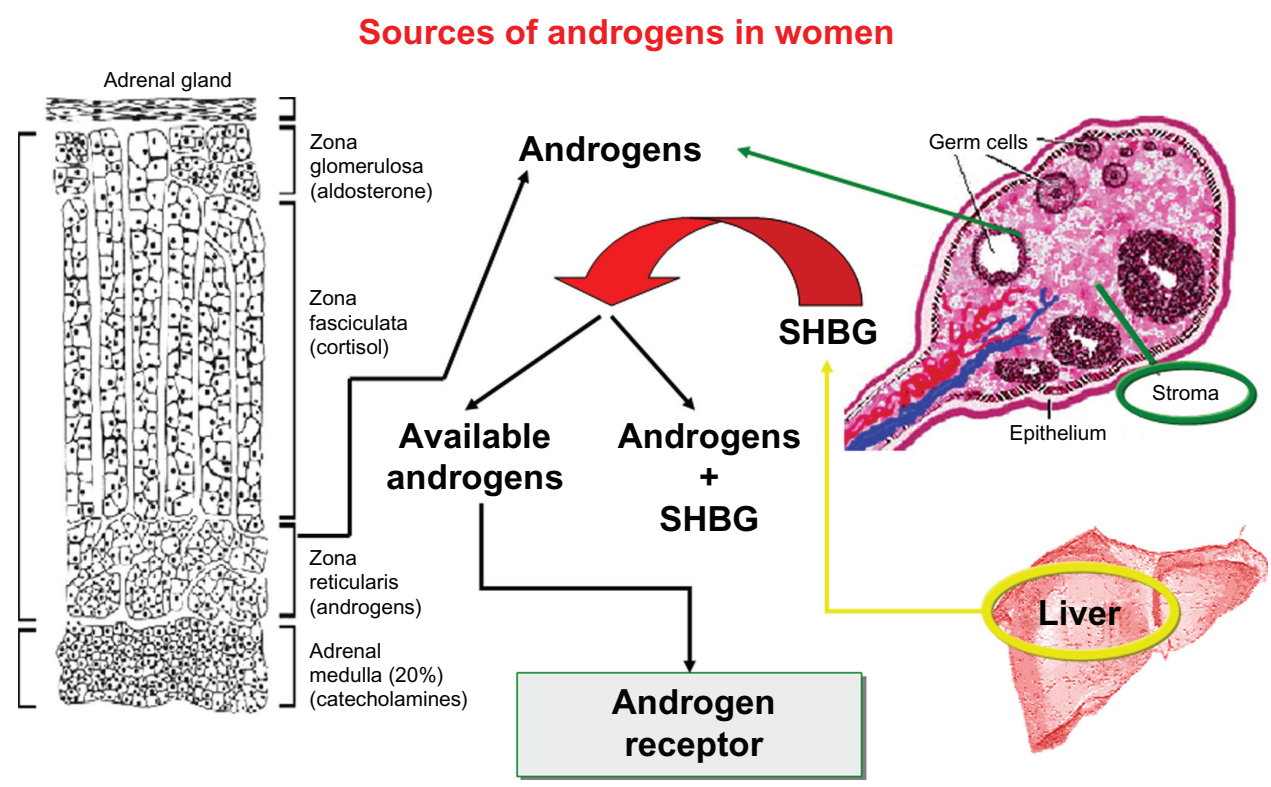

Figure I Sources of androgens in women. In addition to the adrenal gland and the ovarian stroma, the liver and the pilosebaceous unit are represented in relationship to their role in androgen availability and biological properties.

hormone axis. The maintenance of hyperandrogenism is further guaranteed by hyperinsulinemia, via different mechanisms. It is capable of stimulating the pituitary to secrete luteinizing hormone, to favor androgen, and the bioavailability of insulin-like growth factor in relationship to its inhibition of sex hormone-binding globulin and hepatic secretion of insulin-like growth factor binding protein (Figure 3). ${ }^{31}$

Therefore, in the presence of acne and/or other hyperandrogenic states, the aims of treatment are to inhibit ovarian secretion of androgens, inhibit binding of testosterone with its receptor, inhibit the $5 \alpha$-reductase enzyme, and reduce bioavailable androgens.

\section{Treatment of acne with oral contraceptives}

Inhibition of gonadotropin secretion by estroprogestin compounds (oral contraceptives) is followed by a decrease in androgen secretion by the ovary. This effect alone could be

Table I Factors capable of interfering in SHBG secretion

\begin{tabular}{ll}
\hline State or compound & Action \\
\hline Estrogen & Increase \\
Androgens & Reduction \\
Thyroid hormones & Increase \\
Glucocorticoids & Reduction \\
Growth hormone $(\mathrm{Gh})$ & Reduction \\
Obesity & Reduction \\
Hyperinsulinemia & Reduction \\
Hyperprolactinemia & Reduction \\
Danazol & Reduction \\
\hline
\end{tabular}

Abbreviation: SHBG, sex hormone-binding globulin. beneficial in the treatment of acne, but oral contraceptives can exert further antiandrogenic effects in relation to ethinyl estradiol-stimulated secretion of sex hormone-binding globulin, levels of which are inversely related to androgen bioavailability. ${ }^{25}$ However, the properties of the progestin compound may strongly modulate the hypoandrogenic effect of an oral contraceptive. In fact, some progestin compounds themselves bind to both the androgen receptor and sex hormone-binding globulin, with the final effect of high androgen bioavailability. The older progestin compounds, synthesized in the 1960s and 1970s, were designed for use in oral contraceptives. For this reason, a major design target was antigonadotropic action. ${ }^{32}$ In the last two decades, some progestins have been synthesized with the objective of creating an "ideal" progestin. The ideal progestin should be capable of exerting both potent progestagenic and antiestrogenic actions on the endometrium associated with a strong antigonadotropic effect, and have antiandrogenic properties ${ }^{33}$ without binding to sex hormone-binding globulin..$^{25,34}$ The oral contraceptive formulations with these progestin compounds are a specific treatment for acne and for hyperandrogenic symptoms. The additional properties of some estroprogestin oral contraceptive formulations can lead to an overall beneficial effect on quality of life, so much so that they have to be chosen by women requiring a treatment for acne.

The following sections report the results obtained with estroprogestin oral contraceptives containing a progestin compound with antiandrogenic properties, ie, chlormadinone acetate (CMA) or drospirenone. 
Table 2 Mean \pm standard error $(M \pm S E)$ of glucose, insulin, $C$ peptide values, and $C$ peptide/insulin ratio in 154 women with hyperandrogenic symptoms, divided for causes of hyperandrogenism, and in 205 eumenorrheic women with ovulatory cycle and without hyperandrogenic symptoms (control group)

\begin{tabular}{lcllclc}
\hline & $\begin{array}{l}\text { PCOS } \\
(\mathbf{n}=\mathbf{3 2})\end{array}$ & $\begin{array}{l}\text { IH } \\
(\mathbf{n}=\mathbf{7 7})\end{array}$ & $\begin{array}{l}\text { Hyper PRL } \\
(\mathbf{n}=15)\end{array}$ & $\begin{array}{l}\text { Obesity } \\
(\mathbf{n}=15)\end{array}$ & $\begin{array}{l}\text { 2IOH deficit } \\
(\mathbf{n}=15)\end{array}$ & $\begin{array}{l}\text { Control group } \\
(\mathbf{n}=\mathbf{2 0 5})\end{array}$ \\
\hline Glucose (mg/dL) & $78.6 \pm 2.2$ & $79.57 \pm 1.6$ & $86.57 \pm 3.8$ & $81 \pm 2.3$ & $83.14 \pm 3.9$ & $75.6 \pm 6.5$ \\
Insulin (PMol/L) & $93.78 \pm 11.9$ & $73.17 \pm 4.5$ & $70.86 \pm 9.0$ & $116.8 \pm 14.7^{\mathrm{a}}$ & $90.71 \pm 13.4$ & $43.1 \pm 12.6^{\mathrm{b}}$ \\
$\begin{array}{l}\text { C peptide } \\
\text { (PMol/L) }\end{array}$ & $513.0 \pm 82.0$ & $474.0 \pm 35.8$ & $521.0 \pm 154.0$ & $889.0 \pm 185.0^{\mathrm{a}}$ & $582.0 \pm 86.3$ & $252.0 \pm 122.0^{\mathrm{b}}$ \\
C peptide/insulin & $6.29 \pm 0.7$ & $6.73 \pm 0.4$ & $9.07 \pm 2.7$ & $9.03 \pm 2.5$ & $6.84 \pm 1.1$ & $6.25 \pm 3.4$ \\
\hline
\end{tabular}

Notes: ${ }^{a} P<0.05$ vs IH and vs hyperPRL; ${ }^{b} P<0.05$ vs all groups.

Abbreviations: PCOS, polycystic ovarian syndrome; IH, idiopathic hirsutism; HyperPRL, hyperprolactinemia; $2 \mathrm{IOH}$ deficit, deficit of $2 \mathrm{I} \beta$ hydroxylase enzyme.

\section{Oral contraceptives containing chlormadinone acetate}

CMA is a 17-acetoxyprogesterone derivative molecule with a chlorine atom at C6. CMA has a strong affinity for the progesterone receptor (one third higher than for natural progesterone), ${ }^{35}$ contributing to both progesterone activity at the endometrium and prevention of the luteinizing surge. ${ }^{35}$

Similar to natural progesterone, CMA has mild glucocorticoid activity, ${ }^{36,37}$ does not have estrogenic or androgenic activity, ${ }^{37-40}$ but has a potent antiandrogenic effect. ${ }^{37-40}$ Studies in animals ${ }^{41}$ and cells of human prostatic adenocarcinoma in vitro $^{42}$ show that CMA competitively binds to androgen receptors and significantly decreases their transcriptional activity. In addition, CMA is capable of reducing the activity of $5 \alpha$-reductase in the skin. ${ }^{40}$ Lack of binding of CMA with sex hormone-binding globulin ${ }^{43}$ enables the estroprogestin formulation containing ethinyl estradiol and CMA to cause a significant reduction in androgen bioavailability. ${ }^{44}$ Clinical studies of a monophasic estroprogestin oral contraceptive formulation containing ethinyl estradiol $30 \mu \mathrm{g}$ and CMA $2 \mathrm{mg}$ (EE30 + CMA) have shown efficacy in reducing hyperandrogenic symptoms, such as oily skin ${ }^{45}$ and acne or

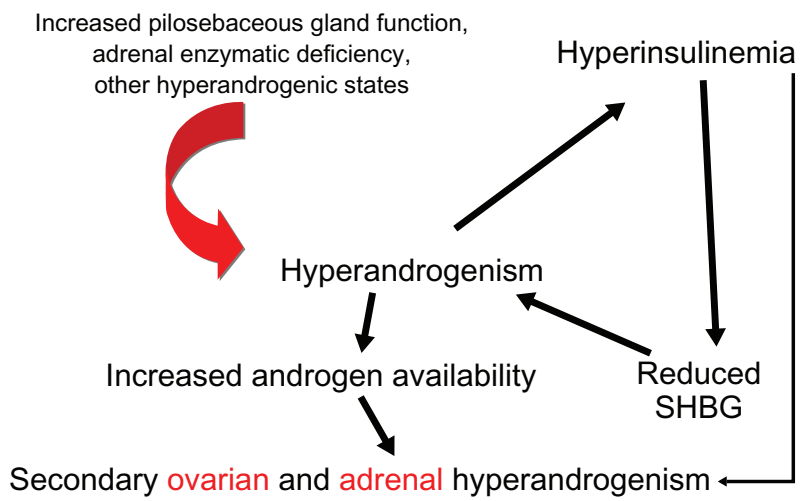

Figure 2 Mechanisms through which hyperinsulinemia dependent on androgen overstimulation can increase androgen secretion and its availability. seborrhea ${ }^{46}$ A placebo-controlled study showed significant efficacy of EE30 + CMA in the resolution of moderate acne. ${ }^{46}$ In healthy eumenorrheic women, EE30 + CMA was effective in balancing the effects of ethinyl estradiol on fluid retention and in reducing fat mass. ${ }^{47}$ In addition, it was demonstrated that EE30 + CMA does not reduce insulin sensitivity, but is capable of improving the lipid profile..$^{48,49}$ These metabolic effects of EE30 + CMA are important in women with hyperandrogenic symptoms, especially those with polycystic ovarian syndrome, in whom the gold standard of estroprogestin treatment is a formulation able to both ameliorate the hyperandrogenic state and be devoid of deleterious effects on metabolic status, particularly glucose-insulin metabolism. A study published by our group ${ }^{50}$ investigated the effects of six cycles of treatment with EE30 + CMA on hyperandrogenic symptoms, androgen levels, glucose tolerance, and body composition in nonobese women with polycystic ovarian syndrome. The results were compared with those obtained in

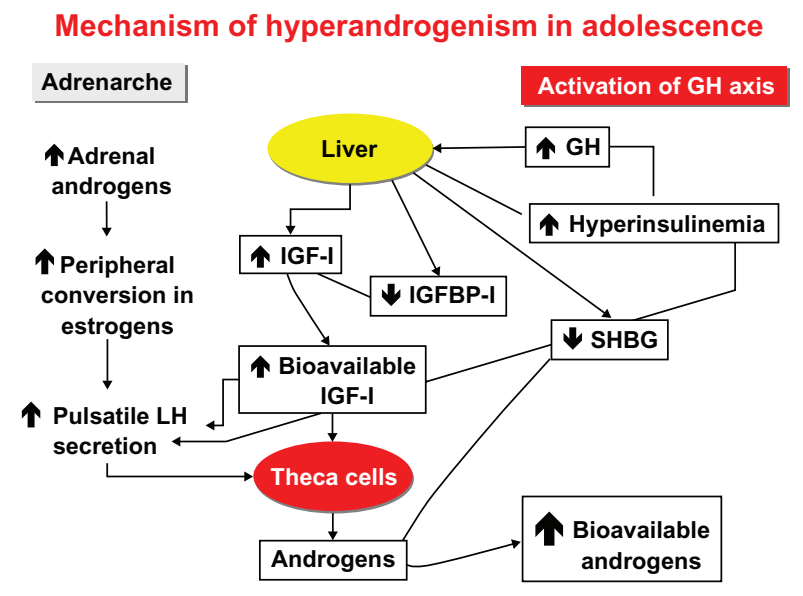

Figure 3 Complex mechanism of hyperandrogenism in adolescence. Increased ovarian androgen secretion is enhanced by the action of insulin and insulin-like growth factors on ovarian stromal cells. Maintenance of hyperandrogenism is further sustained by hyperinsulinemia, through direct stimulation of secretion of luteinizing hormone and inhibition of hepatic secretion of both sex hormone-binding globulin and insulin-like growth factors-binding proteins. 
a similar group of nonobese women with polycystic ovarian syndrome who, over a period of 6 months, did not undergo any treatment. The results showed that six cycles of treatment with EE30 + CMA was associated with a significant improvement in the Plewig-Kigman comedone score $(0.67 \pm 0.16$ vs $2.80 \pm 0.23 ; P<0.05)$ and hirsutism score in treated women with polycystic ovarian syndrome, whereas no changes occurred in their untreated counterparts. At the sixth cycle of $\mathrm{EE} 30$ + CMA, circulating levels of testosterone and androstenedione were significantly lower in the treated women, but remained unchanged in the untreated women. EE30 + CMA also decreased DHEAS levels, which are higher in women with polycystic ovarian syndrome as a consequence of adrenal hyperandrogenism..$^{51,52}$ Finally, the strong capacity of ethinyl estradiol to enhance sex hormone-binding globulin secretion was not counteracted by CMA, which is bound to albumin rather than sex hormone-binding globulin. ${ }^{43}$ The absolute reduction in circulating ovarian and adrenal androgen levels was associated with a significant reduction in their bioavailability, as demonstrated by a significant decrease in the free androgen index, calculated by the appropriate formula. ${ }^{53}$ In addition, the six cycles of EE30 + CMA did not modify the metabolic pattern of hyperinsulinemia or body composition in these women with polycystic ovarian syndrome.

It is known that exogenous androgens reduce insulin sensitivity, ${ }^{28-30}$ and it has been demonstrated that a peripheral increase in androgen activity is associated with altered insulin metabolism. ${ }^{25}$ However, in women with polycystic ovarian syndrome, hyperinsulinemia seems to play a primary role in induction of hyperandrogenism, as demonstrated by several studies showing that reduction of hyperandrogenism is not followed by normalization or improvement in insulin resistance. ${ }^{27,54,55}$ This metabolic finding can be considered an additional beneficial effect of EE30 + CMA.

In 72 young women with moderate-to-severe hirsutism and acne, nine cycles of EE30 + CMA decreased hirsutism and acne scores by up to $81 \%$. Reduction of the antiesthetic effects of hyperandrogenism is coupled with an improvement in female sexual and social self-esteem. ${ }^{56}$ In an observational study of 3771 women, the proportion suffering from acne decreased from $46.5 \%$ at study entry to $14.9 \%$ after 13 cycles of EE30 + CMA. ${ }^{57}$ Another prospective, observational, noninterventional, multicenter study conducted in at least 6800 women younger than 20 years of age recruited from 886 gynecological centers throughout Germany showed that six cycles of treatment with EE30 + CMA achieved a significant reduction $(55 \% ; P<0.001)$ in acne and acne-prone skin. In this study, the beneficial effect of this oral contraceptive on acne was also associated with other favorable effects, including reduction of dysmenorrhea and no effect on body weight, with a mean weight change of less than $1 \mathrm{~kg} .{ }^{58}$ The efficacy of EE30 + CMA in resolution of moderate acne has been demonstrated by a randomized, double-blind, placebo-controlled trial ${ }^{46}$ performed in 387 subjects, aged 18-40 years, with moderate papulopustular acne of the face (8-75 papules and/or pustules). The response rate was significantly $(P=0.0001)$ higher in the EE30 + CMA group $(161 / 251,64.1 \%)$ compared with the placebo group $(55 / 126,43.7 \%) .{ }^{46}$ More recently, an oral contraceptive containing CMA has been dispensed with a different dose of ethinyl estradiol (every pill containing ethinyl estradiol $20 \mu \mathrm{g}+\mathrm{CMA} 2 \mathrm{mg}$ ) and with a novel regimen (administered daily for 24 days, followed by a 4-day placebo interval). With this formulation, a decrease in papules/pustules and comedones was observed in subjects who presented with acne at the baseline visit during 21 cycles of treatment. ${ }^{59}$

In conclusion, oral contraceptives containing CMA appear to exert a favorable effect on acne. They can be recommended for the treatment of acne, not only in view of its strong effect on the main symptom, but also in consideration of its additional beneficial effects, both on quality of life and general health.

\section{Oral contraceptives containing drospirenone}

Drospirenone is an analog of the aldosterone antagonist, spironolactone, and is a unique progestin compound. ${ }^{60-63}$ The pharmacological profile of drospirenone is closely related to that of progesterone. Unlike other available synthetic progestins derived from 19-nortestosterone and $17 \alpha$-hydroxyprogesterone, drospirenone demonstrates both antimineralocorticoid and antiandrogenic activity. The progestagenic potency of drospirenone has been studied in several animal models where it was found to be within the potency range of cyproterone acetate and norethisterone acetate ${ }^{64}$ Studies in humans demonstrated that drospirenone has strong central and peripheral progestational activity, ${ }^{60}$ rendering it suitable for oral contraception. Drospirenone is an antiandrogenic agent, and inhibits androgen receptormediated transcription in a dose-dependent manner. ${ }^{65}$ In vivo experiments of its antiandrogenic potency in inhibition of testosterone-induced prostatic growth in juvenile castrated male rats have shown that drospirenone has a potency almost ten times greater than that of progesterone ${ }^{65}$ and one-third that of cyproterone acetate, but superior to that of spironolactone. ${ }^{61,64}$ The serum half-life of 
drospirenone is approximately 31 hours. It is not bound to sex hormone-binding globulin, with up to $97 \%$ being loosely bound to serum albumin. ${ }^{39}$ This characteristic allows drospirenone to exert its antiandrogenic and antimineralocorticoid properties fully. Although the antiandrogenic action of drospirenone is lower than that of cyproterone acetate, it is enough to be useful in women with acne when combined with ethinyl estradiol. Drospirenone $3 \mathrm{mg}$ has been combined with two different doses of ethinyl estradiol. An oral contraceptive formulation containing ethinyl estradiol $30 \mu \mathrm{g}+$ drospirenone $3 \mathrm{mg}(\mathrm{EE} 30+\mathrm{DRSP})$ is available as a formulation taken for 21 days, followed by 7 pill-free days. The efficacy of this treatment in acne was evaluated in a randomized controlled trial using an oral contraceptive containing ethinyl estradiol $35 \mu \mathrm{g}$ and cyproterone acetate $2 \mathrm{mg}$ (EE35 + CPA). Over a course of nine cycles of treatment, EE30 + DRSP was found to be as efficacious as EE35 + CPA. ${ }^{66}$ Similar results have been found in a comparative study performed over 12 cycles of treatment, in which EE30 + DRSP had an antiandrogenic effect on endocrine and clinical signs similar to that observed with $\mathrm{EE} 35+\mathrm{CPA}^{67}$

The same oral contraceptive formulation containing drospirenone has also been studied in women with polycystic ovarian syndrome. In an open-label study, 20 women with polycystic ovarian syndrome were evaluated. ${ }^{68}$ All women received EE30 + DRSP over six cycles. The 6-month regimen did result in some significant improvements in symptoms of polycystic ovarian syndrome and hormone levels. Hirsutism was significantly decreased, as demonstrated by a significant decrease in the Ferriman-Gallwey score from baseline. Additionally, testosterone levels decreased significantly and sex hormone-binding globulin level increased significantly, with a significant decrease in the free androgen index. Overall, this study demonstrated that oral contraception with drospirenone is effective in decreasing hyperandrogenism and reducing hirsutism (a primary symptom of polycystic ovarian syndrome). In another study of women with polycystic ovarian syndrome, androstenedione, DHEAS, testosterone, and free testosterone levels were reduced when the women were treated with EE30 + DRSP. ${ }^{69}$ The same study showed that the magnitude of the sex hormone-binding globulin increase found with EE30 + DRSP treatment was greater than that found with treatment using $17 \alpha$-hydroxyprogesterone derivatives. This indicates that drospirenone-containing oral contraceptives may be more effective in the treatment of hyperandrogenism than oral contraceptives that use $17 \alpha$ hydroxyprogesterone derivatives as the progestin agents. ${ }^{69}$
A similar study conducted over 12 cycles confirmed the same results. ${ }^{70}$ In addition, there is also evidence that treatment with EE30 + DRSP decreases the severity of acne in women with polycystic ovarian syndrome. ${ }^{71}$

An oral contraceptive containing drospirenone is also available as a combined formulation containing ethinyl estradiol $20 \mu \mathrm{g}$ and drospirenone $3 \mathrm{mg}$ as a 24 day- regimen, followed by 4 days of placebo pills (EE20 + DRSP/24). The shorter hormone-free interval leads to a greater suppression of follicle development and a more stable hormone time frame than the traditional regimes of a 21-day hormone containing pill and 7 days of placebo. As expected, greater pituitary and ovarian suppression are seen with the shorter hormone-free interval. ${ }^{72}$ Thus, this last formulation is capable of enhancing all the properties of drospirenone, including antiandrogenic activity.

Maloney et $\mathrm{al}^{73}$ performed a double-blind study of the therapeutic efficacy of EE20 + DRSP/24 in healthy women aged 14-45 years with moderate acne. The women were randomized to receive EE20 + DRSP/24 $(n=270)$ or placebo $(n=268)$ for six cycles. The percentage reduction from baseline to the final observation of total acne lesions was $46.3 \%$ for the EE20 + DRSP/24 group, which was significantly higher $(P<0.001)$ than that observed in the placebo group $(30.6 \%) .{ }^{73}$ At the end of treatment, the percentage reduction in inflammatory, noninflammatory, and total lesion count in the EE20 + DRSP/24 group was significantly higher than in the placebo group ( $50 \%$ vs $32 \% ; P<0.001) .{ }^{73}$ A similar study was performed by Koltun et $\mathrm{al}^{74}$ in healthy women aged 14-45 years with moderate acne who were randomized to EE20 + DRSP/24 $(n=266)$ or placebo $(n=268)$ for six cycles. At the end of the study, the women treated with the oral contraceptive showed a greater reduction from baseline in inflammatory, noninflammatory, and total lesion counts than the placebo-treated women. The number of women treated with the oral contraceptive who had clear or "almost clear" skin, as rated by the investigators at the end of trial was about four-fold greater than that in the placebo group $(P=0.001)$.

A very interesting observational study was performed in 20 hyperandrogenic women treated with EE20 + DRSP/24, with the aim of evaluating the effects on both acne and parameters of skin quality after a short-term treatment period of 3 months. ${ }^{75}$ At the third cycle of treatment, acne, seborrhea, and circulating androgens were significantly decreased compared with baseline. Corneometry (a parameter related to skin hydration) was significantly increased, whereas transepidermal water loss and erythema (a parameter related to skin 
inflammation) were significantly reduced..$^{75}$ These results are similar to those obtained by the same authors ${ }^{76}$ in a similar group of acne-affected women when using an EE30 + DRSP oral contraceptive formulation.

Other beneficial effects of oral contraceptives containing drosperidone must be considered especially if treatment is required for a long time. The antimineralocorticoid activity of drosperidone plays a key role in the maintenance of body composition, mainly in the reduction of total body water and extracellular water after the first cycles of treatment, which stabilize in subsequent cycles. ${ }^{77}$ This finding could be important for increasing patient compliance with estroprogestin treatment. The same antimineralocorticoid and antiandrogenic properties of drosperidone are very important in explaining the good metabolic tolerability of oral contraceptives containing this progestin compound. Antagonism of the aldosterone and androgen receptor is the mechanism through which the majority of the studies show that drosperidone-containing oral contraceptives are devoid of negative effects, both on insulin-glucose metabolism and lipid metabolism. ${ }^{69,78}$ All these effects have to be considered in the choice of an oral contraceptive, particularly in hyperandrogenic women, in whom androgen hyperactivity exposes them to a greater risk of metabolic disorders and their consequences on health.

\section{Conclusion}

In conclusion, oral contraceptives, mainly those containing progestin compounds with antiandrogenic properties, are often helpful for acne vulgaris, but often they require topical and systemic therapies to achieve an adequate result.

\section{Acknowledgment}

The authors thank Franca Fadda for typing the manuscript and Kate Jenkins for revising English grammar. This research was partially supported by Benessere Donna Onlus Foundation (Cagliari, Italy).

\section{Disclosure}

The authors report no conflicts of interest in this work.

\section{References}

1. Tan JK. Psychosocial impact of acne vulgaris: evaluating the evidence. Skin Therapy Lett. 2004;9(7):1-39.

2. Magin P, Adams J, Heading G, Pond D, Smith W. Psychological sequelae of acne vulgaris: results of a qualitative study. Can Fam Physician. 2006; 52(8):978-979.

3. Purvis D, Robinson E, Merry S, Watson P. Acne, anxiety, depression and suicide in teenagers: a cross-sectional survey of New Zealand secondary school students. J Paediatr Child Health. 2006;42(12):793-796.
4. Kellett SC, Gawkrodger DJ. The psychological and emotional impact of acne and the effect of treatment with isotretinoin. $\mathrm{Br} J$ Dermatol. 1999; 140(2):273-282.

5. Rapp DA, Brenes GA, Feldman SR, et al. Anger and acne: implications for quality of life, patient satisfaction and clinical care. Br J Dermatol. 2004;151(1):183-189.

6. Dalgard F, Gieler U, Holm JØ, Bjertness E, Hauser S. Self-esteem and body satisfaction among late adolescents with acne: results from a population survey. J Am Acad Dermatol. 2008;59(5):746-751.

7. Collier CN, Harper JC, Cafardi JA, et al. The prevalence of acne in adults 20 years and older. J Am Acad Dermatol. 2008;58(1):56-59.

8. Norris JF, Cunliffe WJ. A histological and immunocytochemical study of early acne lesions. Br J Dermatol. 1988;118(5):651-659.

9. Thiboutot D. Regulation of human sebaceous glands. J Invest Dermatol. 2004;123(1):1-12.

10. Deplewski D, Rosenfield RL. Growth hormone and insulin-like growth factors have different effects on sebaceous cell growth and differentiation. Endocrinology. 1999;140(9):4089-4094.

11. Kim M, Ciletti N, Michel S, Reichert U, Rosenfield R. The role of specific retinoid receptors in sebocyte growth and differentiation in culture. J Invest Dermatol. 2000;114(2):349-353.

12. Rosenfield RL, Deplewski D, Kentsis A, Ciletti N. Mechanisms of androgen induction of sebocyte differentiation. Dermatology. 1998; 196(1):43-46.

13. Strauss JS, Kligman AM, Pochi PE. The effect of androgens and estrogens on human sebaceous glands. J Invest Dermatol. 1962;39(8):139-155.

14. Zouboulis C, Korge B, Akamatsu H, et al. Effects of 13-cis-retinoic acid, all-trans-retinoic acid, and acitretin on the proliferation, lipid synthesis and keratin expression of cultured human sebocytes in vitro. $J$ Invest Dermatol. 1991;96(5):792-797.

15. Choudhry R, Hodgins M, Van der Kwast T, Brinkmann A, Boersma W. Localization of androgen receptors in human skin by immunohistochemistry: implications for the hormonal regulation of hair growth, sebaceous glands and sweat glands. J Endocrinol. 1992;133(3):467-475.

16. Liang T, Hoyer S, Yu R, et al. Immunocytochemical localization of androgen receptors in human skin using monoclonal antibodies against the androgen receptor. J Invest Dermatol. 1993;100(5):663-666.

17. Thiboutot D, Harris G, Iles V, Cimis G, Gilliland K, Hagari S. Activity of the type 15 alpha-reductase exhibits regional differences in isolated sebaceous glands and whole skin. J Invest Dermatol. 1995;105(2): 209-214.

18. Fritsch M, Orfanos C, Zouboulis C. Sebocytes are the key regulators of androgen homeostasis in human skin. J Invest Dermatol. 2001;116(5): 793-800.

19. Lobo RA. Androgen excess. In: Mishell DR, Davajan V, Lobo RA, editors. Infertility, Contraception and Reproductive Endocrinology. 3rd ed. Boston, MA: Blackwell Scientific Publications; 1991.

20. Breckwoldt M, Zahradnik HP, Wieacker P. Hirsutism, its pathogenesis. Hum Reprod. 1989;4(6):601-604.

21. Chen W, Thiboutot D, Zouboulis C. Cutaneous androgen metabolism: basic research and clinical perspectives. J Invest Dermatol. 2002;119(5): 992-1007.

22. Smythe C, Greenall M, Kealey T. The activity of HMG-CoA reductase and acetyl- CoA carboxylase in human apocrine sweat glands, sebaceous glands and hair follicles is regulated by phosphorylation and by exogenous cholesterol. J Invest Dermatol. 1998;111(1):139-148.

23. Cassidy D, Lee C, Laker M, Kealey T. Lipogenesis in isolated human sebaceous glands. FEBS Lett. 1986;200(1):173-176.

24. Proksch E, Feingold KR, Elias PM. Epidermal HMG CoA reductase activity in essential fatty acid deficiency: barrier requirements rather than eicosanoid generation regulate cholesterol synthesis. $J$ Invest Dermatol. 1992;99(2):216-220.

25. Vrbíková J, Cibula D. Combined oral contraceptives in the treatment of polycystic ovary syndrome. Hum Reprod Update. 2005;11(3): 277-291.

26. Liu PY, Death AK, Handelsman DJ. Androgens and cardiovascular disease. Endocr Rev. 2003;24(3):313-340. 
27. Paoletti AM, Cagnacci A, Orrù M, Ajossa S, Guerriero S, Melis GB. Treatment with flutamide improves hyperinsulinemia in women with idiopathic hirsutism. Fertil Steril. 1999;72(3):448-453.

28. Holmang A, Larsson BM, Brzezinska Z, Bjorntorp P. Effects of short-term testosterone exposure on insulin sensitivity of muscles in female rats. Am J Physiol. 1992;262(6 Pt 1):E851-E855.

29. Hennes MM, Shrago E, Kissebach AH. Receptor and postreceptor effects of free fatty acids (FFA) on hepatocyte insulin dynamics. Int $J$ Obes. 1990;14(10):831-841.

30. Svedberg J, Stromblad G, Wirth A, Smith U, Bjorntorp P. Fatty acids in the portal vein of the rat regulate hepatic insulin clearance. $J$ Clin Invest. 1991;88(6):2054-2058.

31. Witchel SF, Plant TM. Puberty: gonadarche and adrenarche. In: Strauss JF, Barbieri RL, editors. Yen and Jaffe's Reproductive Endocrinology. Physiology, Pathophysiology, and Clinical Management. 5th ed. Philadelphia, PA: Elsevier Saunders; 2004.

32. Henzl MR, Edwards JA. Pharmacology of progestins: $17 \alpha-$ hydroxyprogesterone derivatives and progestins of the first and second generation. In: Sitruk-Ware R, Mishell DR Jr, editors. Progestins and Antiprogestins in Clinical Practice. New York: Marcel Dekker; 2000.

33. Sitruk-Ware R. Pharmacological profile of progestins. Maturitas. 2008; 61(1-2):151-157.

34. Wiegratz I, Kutschera E, Lee JH, et al. Effect of four different oral contraceptives on various sex hormones and serum-binding globulins. Contraception. 2003;67(1):25-32.

35. Kuhl H. Pharmacology of progestins. Basic Aspects-Progesterone Derivatives. Menopause Rev. 2001;6:9-16.

36. Druckmann R. Profile of the progesterone derivative chlormadinone acetate - pharmocodynamic properties and therapeutic applications. Contraception. 2009;79(4):272-281.

37. Schneider J, Kneip C, Jahnel U. Comparative effects of chlormadinone acetate and its 3alpha- and 3beta-hydroxy metabolites on progesterone, androgen and glucocorticoid receptors. Pharmacology. 2009;84(2): $74-81$.

38. Curran MP, Wagstaff AJ. Ethinylestradiol/chlormadinone acetate. Drugs. 2004;64(7):751-760.

39. Schindler AE, Campagnoli C, Druckmann R, et al. Classification and pharmacology of progestins. Maturitas. 2003;46 Suppl 1:S7-S16.

40. Raudrant D, Rabe T. Progestogens with antiandrogenic properties. Drugs. 2003;63(5):463-492.

41. Murakoshi M, Ikeda R, Fukui N. The effects of chlormadinone acetate (CMA), antiandrogen, on the pituitary, testis, prostate and adrenal gland of the dog with spontaneous benign prostatic hyperplasia. JToxicol Sci. 2001;26(3):119-127.

42. Térouanne B, Paris F, Servant N, Georget V, Sultan C. Evidence that chlormadinone acetate exhibits antiandrogenic activity in androgen-dependent cell line. Mol Cell Endocrinol. 2002;198(1-2): 143-147.

43. Bouchard P. Chlormadinone acetate (CMA) in oral contraception - a new opportunity. Eur J Contracept Reprod Health Care. 2005;10 Suppl 1:7-11.

44. Jung-Hoffmann C, Kuhl H. Divergent effects of two low-dose oral contraceptives on sex hormone-binding globulin and free testosterone. Am J Obstet Gynecol. 1987;156(1):199-203.

45. Schramm G, Steffens D. A 12-month evaluation of the CMA-containing oral contraceptive Belara: efficacy, tolerability and anti-androgenic properties. Contraception. 2003;67(4):305-312.

46. Plewig G, Cunliffe WJ, Binder N, Höschen K. Efficacy of an oral contraceptive containing EE $0.03 \mathrm{mg}$ and CMA $2 \mathrm{mg}$ (Belara) in moderate acne resolution: a randomized, double-blind, placebocontrolled Phase III trial. Contraception. 2009;80(1):25-33.

47. Uras R, Orrù M, Etzi R, et al. Evidence that in healthy young women, a six-cycle treatment with oral contraceptive containing $30 \mathrm{mcg}$ of ethinylestradiol plus $2 \mathrm{mg}$ of chlormadinone acetate reduces fat mass. Contraception. 2009;79(2):117-121.
48. Cagnacci A, Ferrari S, Tirelli A, Zanin R, Volpe A. Route of administration of contraceptives containing desogestrel/etonorgestrel and insulin sensitivity: a prospective randomized study. Contraception. 2009;80(1): 34-39.

49. Winkler UH, Sudik R. The effects of two monophasic oral contraceptives containing $30 \mathrm{mcg}$ of ethinyl estradiol and either $2 \mathrm{mg}$ of chlormadinone acetate or $0.15 \mathrm{mg}$ of desogestrel on lipid, hormone and metabolic parameters. Contraception. 2009;79(1):15-23.

50. Uras R, Orrù M, Pani F, et al. Endocrinological, metabolic and clinical features of treatment with oral contraceptive formulation containing ethinylestradiol plus chlormadinone acetate in nonobese women with polycystic ovary syndrome. Contraception. 2010;82(2):131-138.

51. Huang A, Brennan K, Azziz R. Prevalence of hyperandrogenemia in the polycystic ovary syndrome diagnosed by the National Institutes of Health 1990 criteria. Fertil Steril. 2010;93(6):1938-1941.

52. Kumar A, Woods KS, Bartolucci AA, Azziz R. Prevalence of adrenal androgen excess in patients with the polycystic ovary syndrome (PCOS). Clin Endocrinol (Oxf). 2005;62(6):644-649.

53. Morley JE, Patrick P, Perry III HM. Evaluation of assays available to measure free testosterone. Metabolism. 2002;51(5):554-559.

54. Geffner ME, Kaplan SA, Bersch N, Golde DW, Landaw EM, Chang RJ. Persistence of insulin resistance in polycystic ovarian disease after inhibition of ovarian steroid secretion. Fertil Steril. 1986;45(3): 327-333.

55. Dunaif A, Green G, Futterweit W, Dobrjansky A. Suppression of hyperandrogenism does not improve peripheral or hepatic insulin resistance in the polycystic ovary syndrome. J Clin Endocrinol Metab. 1990;70(3): 699-704.

56. Caruso S, Rugolo S, Agnello C, Romano M, Cianci A. Quality of sexual life in hyperandrogenic women treated with an oral contraceptive containing chlormadinone acetate. $J$ Sex Med. 2009;6(12):3376-3384.

57. Pushparajah DS, Röhm P, Höschen K, Albers D, Nowack C. Safety data and beneficial effects of the combined oral contraceptive ethinylestradiol

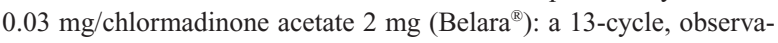
tional study in routine clinical practice. Clin Drug Investig. 2011;31(2): $121-134$.

58. Anthuber S, Schramm GA, Heskamp ML. Six-month evaluation of the benefits of the low-dose combined oral contraceptive chlormadinone acetate $2 \mathrm{mg}$ /ethinylestradiol $0.03 \mathrm{mg}$ in young women: results of the prospective, observational, non-interventional, multicentre TeeNIS study. Clin Drug Investig. 2010;30(4):211-220.

59. Brucker C, Hedon B, The HS, Höschen K, Binder N, Christoph A. Long-term efficacy and safety of a monophasic combined oral contraceptive containing $0.02 \mathrm{mg}$ ethinylestradiol and $2 \mathrm{mg}$ chlormadinone acetate administered in a 24/4-day regimen. Contraception. 2010;81(6): 501-509.

60. Oelkers W, Berger V, Bolik A, et al. Dihydrospirenone, a new progestogen with antimineralocorticoid activity: effects on ovulation, electrolyte excretion, and the renin-aldosterone system in normal women. J Clin Endocrinol Metab. 1991;73(4):837-842.

61. Elger W, Beier S, Pollow K, Garfield R, Shi SQ, Hillisch A. Conception and pharmacological profile of drospirenone. Steroids. 2003;68(10-13): 891-905.

62. Philibert D, Bouchoux F, Degryse M, Lecaque D, Petit F, Gaillard. The pharmacological profile of a novel norpregnane progestin (trimegestone). Gynecol Endocrinol. 1999;13(5):316-326.

63. Krattenmacher R. Drospirenone: pharmacology and pharmacokinetics of a unique progestogen. Contraception. 2000;62(1):29-38.

64. Muhn P, Krattenmacher R, Beier S, Elger W, Schillinger E. Drospirenone: a novel progestogen with antimineralocorticoid and antiandrogenic activity. Pharmacological characterization in animal models. Contraception. 1995;51(2):99-110.

65. Fuhrmann U, Krattenmacher R, Slater EP, Fritzemeier KH. The novel progestin drospirenone and its natural counterpart progesterone: biochemical profile and antiandrogenic potential. Contraception. 1996; 54(4):243-251. 
66. van Vloten WA, van Haselen CW, van Zuuren EJ, Gerlinger C, Heithecker R. The effect of 2 combined oral contraceptives containing either drospirenone or cyproterone acetate on acne and seborrhoea. Cutis. 2002;69(4 Suppl):2-15.

67. Batukan C, Muderris II, Ozcelik B, Ozturk A. Comparison of two oral contraceptives containing either drospirenone or cyproterone acetate in the treatment of hirsutism. Gynecol Endocrinol. 2007;23(1):38-44.

68. Pehlivanov B, Mitkov M. Efficacy of an oral contraceptive containing drospirenone in the treatment of women with polycystic ovary syndrome. Eur J Contracept Reprod Health Care. 2007;12(1):30-35.

69. Guido M, Romualdi D, Giuliani M, et al. Drospirenone for the treatment of hirsute women with polycystic ovary syndrome: a clinical, endocrinological, metabolic pilot study. J Clin Endocrinol Metab. 2004; 89(6):2817-2823.

70. Batukan C, Muderris II. Efficacy of a new oral contraceptive containing drospirenone and ethinyl estradiol in the long-term treatment of hirsutism. Fertil Steril. 2006;85(2):436-440.

71. Palep-Singh M, Mook K, Barth J, Balen A. An observational study of Yasmin in the management of women with polycystic ovary syndrome. J Fam Plann Reprod Health Care. 2004;30(3):163-165.

72. Bruni Bresciani V. Extracontraceptive benefits of EE/DRSP (Yaz) in $24+4$ day regimen. Minerva Ginecol. 2010;62(3):261-266.

73. Maloney JM, Dietze P Jr, Watson D, et al. Treatment of acne using a 3-milligram drospirenone/20-microgram ethinyl estradiol oral contraceptive administered in a 24/4 regimen: a randomized controlled trial. Obstet Gynecol. 2008;112(4):773-781.
74. Koltun W, Lucky AW, Thiboutot D, et al. Efficacy and safety of $3 \mathrm{mg}$ drospirenone $/ 20 \mathrm{mcg}$ ethinylestradiol oral contraceptive administered in 24/4 regimen in the treatment of acne vulgaris: a randomized, double-blind, placebo-controlled trial. Contraception. 2008;77(4): 249-256.

75. Lello S, Pacifico V, Primavera G, et al. Short-term effect of an estroprogestin containing ethinylestradiol $20 \mathrm{mcg}+$ drospirenone $3 \mathrm{mg}$ in $24+4$ regimen at hormonal and cutaneous level in ovarian hyperandrogenism. Minerva Ginecol. 2010;62(6):509-513.

76. Lello S, Primavera G, Colonna L, et al. Effect on skin and hormonal hyperandrogenic manifestations of an oral estroprogestin association containing ethynilestradiol $30 \mathrm{mg}$ and drospirenone $3 \mathrm{mg}$. Minerva Ginecol. 2008;60(3):239-243.

77. Fruzzetti F, Lello S, Lazzarini V, et al. The oral contraceptive containing 30 microg of ethinylestradiol plus $3 \mathrm{mg}$ of drospirenone is able to antagonize the increase of extracellular water occurring in healthy young women during the luteal phase of the menstrual cycle: an observational study. Contraception. 2007;75(3):199-203.

78. Mancini F, Cianciosi A, Persico N, Facchinetti F, Busacchi P, Battaglia C. Drospirenone and cardiovascular risk in lean and obese polycystic ovary syndrome patients: a pilot study. Am J Obstet Gynecol. 2010;202(2):169. $\mathrm{e} 1-\mathrm{e} 8$.
Open Access Journal of Clinical Trials

\section{Publish your work in this journal}

The Open Access Journal of Clinical Trials is an international, peerreviewed, open access journal publishing original research, reports, editorials, reviews and commentaries on all aspects of clinical trial design, management, legal, ethical and regulatory issues, case record form design, data collection, quality assurance and data auditing

\section{Dovepress}

methodologies. The manuscript management system is completely online and includes a very quick and fair peer-review system, which is all easy to use. Visit http://www.dovepress.com/testimonials.php to read real quotes from published authors. 